\section{TÀI LIÊU THAM KHẢO}

1. Chính phủ (2015). Chiến lược quốc gia về dinh dưỡng giai đoan 2011 - 2020 và tầm nhìn đến năm 2030.

2. Chính phủ (2016). Chương trình sữa học đường cải thiện tình trạng dinh dưỡng góp phân nâng cao tầm vóc trẻ em mâuu giáo và tiểu học đến năm 2020.

3. Best C., Neufingerl N., Del Rosso J.M., et al. (2011). Can multi-micronutrient food fortification improve the micronutrient status, growth, health, and cognition of schoolchildren? a systematic review. Nutr Rev, 69(4), 186-204.

4. World Health Organization (2013). Essential
Nutrition Actions: improving maternal, newborn, infant and young child health and nutrition.

5. World Health Organization (2007). The new WHO child growth standards. Bull World Heal Organ, 52(1), 13-17.

6. Flodin N.w. (1997). The metabolic roles, pharmacology, and toxicology of lysine. J Am Coll Nutr, 16(1), 7-21.

7. Gombart A.F., Pierre A., and Maggini S. (2020). A Review of Micronutrients and the Immune System-Working in Harmony to Reduce the Risk of Infection. Nutrients, 12(1), 123-133.

\title{
THAY ĐỔI GIÁ TRI qHBsAg Ở BỆNH NHÂN VIÊM GAN VI RÚT B MẠN KHI ĐIỀU TRI BẰNG TENOFOVIR DISOPROXIL FUMARATE HOĂC TENOFOVIR ALAFENAMIDE
}

\section{TÓM TẮT}

Mục tiêu: Khảo sát sự thay đổi qHBsAg ở bệnh nhân (BN) HBV man điểu trị tenofovir disoproxil fumarate (TDF) hoắc tenofovir alafenamide (TAF). Đối tượng và phương pháp nghiên cứu: Nghiên cứu cắt ngang mô tả thực hiện trên những $\mathrm{BN} H B V$ man điều trị ngoại trú với TDF 300mg hoặc TAF 25mg tại phòng khám Viêm gan ,bênh viện Đại học Y Dước TiP Hồ Chí Minh từ tháng 01/2017 đến 12/2020. Tiển hành đánh giá sự thay đổi qHBsAg khi điều trị với TDF hoăc TAF. Kết quả: Nghiên cứu có 250 BN, trong đó $160 \mathrm{BN}(64 \%)$ được điều trị với TDF và 90 BN (36\%) được điều trị TAF. Thời gian điều trị trung bình của nhóm TDF là 4,1 năm và ở nhóm TAF là 2,5 năm. Giá trị qHBsAg trung bình tại thời điểm bắt đầu nghiên cứu của nhóm $B N$ điều trị TDF là $3,0 \pm 0,8\left(\log _{10}\right.$ $\mathrm{UI} / \mathrm{ml}$ ) cao hơn có ý nghĩa so với nhóm BN đang điêu trị TAF $(2,7 \pm 0,9$ với $p=0,02)$. Trong nhóm điêuu trị với TDF, giá trị qHBsAg trung bình sau 12 tuần giảm không có ý nghĩa thống kê so với thời điểm bắt ( $p=$ $0,2)$ nhưng giảm có ý nghĩa tại thời điểm 24 tuần so với ban đầu $(p=0,02)$. Ớ nhóm điều trị với TAF, giá trị qHBsAg giảm không có ý nghĩa ở thời điểm sau 12 tuần $(p=0,8)$ và 24 tuần $(p=0,4)$. Kết luân: Nghiên cứu cho thấy giá trị qHBsAg giám có ý nghĩa tại thời điểm 24 tuần trong quá trình điều trị TDF, tuy nhiên giá trị qHBsAg giảm không có ý nghĩa trong quá trình điều trị TAF thời gian ngắn. Cần có nhiều nghiên cứu với cỡ mẫu lớn hơn, đa trung tâm và thời gian theo dõi dài hơn đến đánh giá vai trò của thuốc tới sự thay đổi qHBsAg.

Tư khoá: qHBsAg, Viêm gan B mạn, TDF, TAF

\footnotetext{
${ }^{1}$ Đại học Y Dược Thành phố Hồ Chí Minh Bềnh viên Chơ Rẫy, Thành phố Hồ Chí Minh Chịu trách nhiệm chính: Võ Duy Thông Email: duythong@ump.edu.vn Ngày nhận bài: 9.4.2021

Ngày phản biên khoa hoc: 24.5.2021

Ngày duyệt bài: 9.6.2021
}

Võ Duy Thông1,2, Võ Ngọc Diễm ${ }^{1}$

\section{SUMMARY \\ CHANGE OF qHBsAg VALUE IN CHRONIC HEPATITIS B PATIENTS TREATED WITH TENOFOVIR DISOPROXIL FUMARATE OR TENOFOVIR ALAFENAMIDE}

Objectives: To investigate the change in qHBsAg in chronic HBV patients treated with tenofovir disoproxil fumarate (TDF) or tenofovir alafenamide (TAF). Methods: A descriptive cross-sectional study was conducted on chronic HBV outpatients treated with TDF $300 \mathrm{mg}$ or TAF $25 \mathrm{mg}$ at the Hepatitis clinic, Ho Chi Minh City University of Medicine and Pharmacy Hospital from January 2017 to December 2020. The qHBsAg change was evaluated in patients treated with TDF or TAF. Results: There were 250 patients included in this study, of which 160 patients (64\%) were treated with TDF and 90 patients (36\%) with TAF. The mean duration of treatment in the TDF group was 4.1 years and in the TAF group was 2.5 years. The mean baseline qHBsAg value in TDF group $(3.0 \pm 0.8(\log 10 \mathrm{UI} / \mathrm{ml}))$ was significantly higher than that in TAF group $(2.7 \pm 0.9), p=0.02$. In the TDFtreated group, the mean qHBsAg value at 12 weeks was not significantly different, compared to that at baseline $(p=0.2)$, but the qHBsAg decreased significantly at 24 weeks $(p=0.02)$. In the TAFtreated group, the mean $\mathrm{qHBsAg}$ value was not significantly diferent at 12 weeks $(p=0.8)$ and 24 weeks $(p=0.4)$ compared to baseline one. Conclusion: The study showed that qHBsAg value decreased significantly at 24 weeks during TDF treatment. However, qHBsAg value did not decrease significantly during short-term TAF treatment. More studies with larger sample sizes, multicenters and longer follow-up are needed to evaluate the effectiveness of drugs in the change of qHBsAg.

Keywords: qHBsAg, Chronic Hepatitis B, TDF, TAF

\section{I. ĐĂT VẤN ĐỀ}

Theo báo cáo của Tổ chức y tễ thế giới vào 
năm 2015 [1], có hơn 2 tỉ người đã nhiễm vi rút viêm gan $B$ (HBV) và gần 240 triệu người bị nhiễm HBV mạn, đặc biệt ở các nước có thu nhập thấp và trung bình. Việt Nam được xếp vào vùng lưu hành cao, với tỷ lệ nhiễm $\mathrm{HBV} \geq 8 \%$. Một số nghiên cứu ở các tỉnh miền Bắc Việt Nam cho thấy tỷ lệ mang $\mathrm{HBsAg}$ là $18,8 \%$ trong nghiên cứu của Hipgrave D B. (2003) [2]. Các biến chứng chính của nhiễm HBV mạn là xơ gan và ung thư biểu mô tế bào gan (HCC). Định lượng cccDNA (DNA vòng đóng đồng hóa trị) trong gan rất có giá trị để xem xét hiệu quả của một phương thức điều trị. Tuy nhiên, muốn xác định cccDNA trong gan phải làm sinh thiết gan là một thủ thuật xâm lấn, do đó nếu có một hoặc nhiều chỉ điểm huyết thanh để nhận biểt được cccDNA trong gan thì có ý nghĩa thực tiễn lâm sàng rất quan trọng. Có nhiều nghiên cứu đã chứng minh được mối tương quan giữa qHBsAg (Quantitative hepatitis B surface antigen: Định lượng kháng nguyên bề mặt viêm gan vi rút $B$ ) và cccDNA [3]. Trong nhóm thuốc các đồng phân nucleos(t)ides, tenofovir, entecavir (ETV) có hiệu quả ức chế vi rút mạnh và mức độ kháng thuốc thấp so với các thuốc khác. Cơ chế tác dụng của tenofovir là ức chế sao chép ngược không cho RNA chuyển thành DNA. Thuốc tenofovir có ưu điểm rất dễ sử dụng, an toàn, dung nạp tốt và được chứng minh có thể cải thiện được những thay đổi mô học [4]. Mục đích của nghiên cứu nhằm khảo sát sự thay đổi qHBsAg ở BN viêm gan vi rút $B$ mạn điêuu trị tenofovir disoproxil fumarate (TDF) hoặc tenofovir alafenamide (TAF).

\section{II. ĐỐI TƯỢNG VÀ PHƯƠNG PHÁP NGHIÊN CỨU}

Đối tượng nghiên cứu. Bệnh nhân ngoại trú từ 18 tuổi trở lên được chẩn đoán xác định HBV mạn điều trị ngoại trú với TDF $300 \mathrm{mg}$ hoăc TAF 25mg tại phòng khám Viêm gan ,bệnh viện Đại học Y Dược TP Hồ Chí Minh.

Tiểu chuẩn loại trừ: Đồng nhiễm viêm gan vi rút $C, H I V$. Có bệnh gan cấp tính do viêm gan vi rút $A$, bệnh lý gan do rượu, do thuốc hay nguyên nhân bệnh lý gan khác.

Phương pháp nghiên cứu. Nghiên cứu cắt ngang mô tả

Cõ̃ mẫu: Tất cả BN thỏa tiêu chuẩn chọn mẫu và không có tiêu chuẩn loại trừ.

Chúng tôi tiến hành thu thập số liệu từ hồ sơ bệnh án ngoại trú tại phòng khám viểm gan. Hồi cứu tất cả các $\mathrm{BN}$ đến khám tại phòng khám từ tháng 1/2017 đến 12/2020, thỏa tiêu chuẩn chọn bệnh, không vi phạm tiêu chuẩn loại trừ. Ghi nhận các thông tin bằng bảng thu thập số liệu.

Phân tích số liệu. Phân tích số liệu bằng phần mềm Stata 14.0. Các mối liên hệ được kiểm định bằng phép kiểm Chi bình phương với $p<0,05$ được xem là có ý nghĩa thống kê.

Vấn đề đạo đức. Đề cương nghiên cứu đã được Hội đồng nghiên cứu khoa học của trường Đại học Y Dược TP. Hồ Chí Minh thông qua và được tiến hành đảm bảo tuân thủ các nguyên tắc đạo đức trong nghiên cứu $Y$ học.

\section{KẾT QUẢ NGHIÊN CỨU}

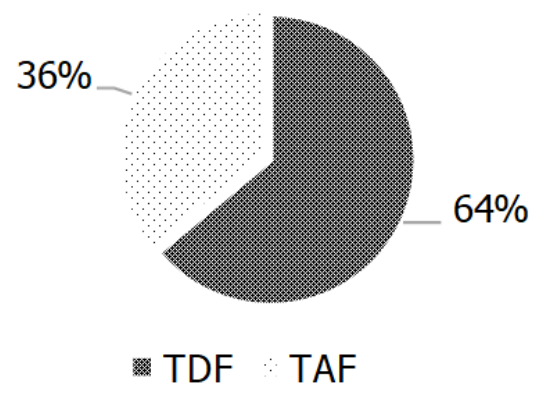

Hinh 1. Phân bố dân số nghiên cứu theo phân nhóm thuốc điều tri

Kết quả nghiên cứu chung tồi thu nhận có 250 BN. Tuổi trung bình của tổng dân số nghiên cứu là $44,3 \pm 12,5$ tuổi, cao nhất là 81 tuổi, thấp nhất là 19 tuổi. Trong đó có $68,0 \%$ BN nam, tỷ lệ nam/ nữ là $2,1 / 1$. Phân nhóm điều trị, kết quả có $160(64 \%)$ được điều trị với TDF và 90 (36\%) BN được điêuu trị TAF (Hình 1). Thời gian điêu trị trung bình của nhóm TDF là 4,1 năm và ở nhóm TAF là 2,5 năm.

Khi so sánh giá trị qHBsAg trung bình tại thời điểm bắt đầu nghiên cứu của nhóm BN điều trị TDF là $3,0 \pm 0,8\left(\log _{10} \mathrm{UI} / \mathrm{ml}\right)$ cao hơn có ý nghĩa so với nhóm BN đang điều trị TAF $(2,7 \pm$ 0,9 với $p=0,02$ ) (Hình 2).

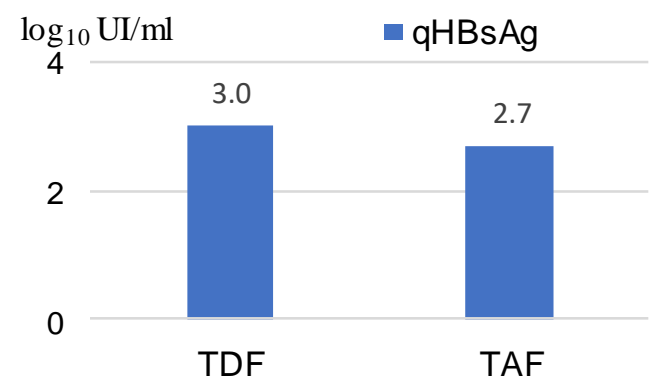

Hình 2. Đặc điểm qHBsAg theo phân nhóm thuốc điều trị

Trong nhóm BN được điêu trị TDF, sau 12 tuần theo dõi ghi nhận được 31 BN có kết quả xét nghiệm qHBsAg, giá trị qHBsAg trung bình 
giảm không đáng kể so với thời điểm bắt đầu theo dõi (giảm $0,2 \log _{10} \mathrm{UI} / \mathrm{ml}, \mathrm{p}=0,2$ ). Còn tại thời điểm 24 tuần, ghi nhận được 58 BN với giá trị qHBsAg trung bình là $2,7 \pm 0,9\left(\log _{10} \mathrm{UI} / \mathrm{ml}\right)$, giảm $0,3 \log _{10} \mathrm{UI} / \mathrm{ml}$ so với thời điểm bắt đầu theo dõi, $p=0,02$.

Trong nhóm BN điều trị TAF, ghi nhận được $20 \mathrm{BN}$ tại thời điểm 12 tuần với giá trị qHBsÁg trung bình là $2,6 \pm 1,0\left(\log _{10} \mathrm{UI} / \mathrm{ml}\right)$, giảm không có ý nghĩa (mức giảm $0,1 \log _{10} \mathrm{UI} / \mathrm{ml}$ ). Tương tự, tại thời điểm 24 tuần, ghi nhận được giá trị qHBsAg trung bình của $29 \mathrm{BN}$, với mức giảm là $0,2 \log _{10} \mathrm{UI} / \mathrm{ml}$, giảm không có ý nghĩa so với thời điểm bắt đầu theo dõi.

Bảng 1. Đặc điểm qHBsAg theo diễn tiến thời gian trong từng phân nhóm

\begin{tabular}{|c|c|c|c|c|}
\hline \multicolumn{5}{|c|}{ Nhóm bệnh nhân TDF } \\
\hline & & $\begin{array}{c}0 \text { tuân } \\
(n= \\
160)\end{array}$ & $\begin{array}{l}12 \text { tuân } \\
(\mathrm{n}=31)\end{array}$ & $\begin{array}{l}24 \text { tuần } \\
(n=58)\end{array}$ \\
\hline qHBsAg & Giá tri & $3,0 \pm 0,8$ & $2,8 \pm 1,0$ & $2,7 \pm 0,9$ \\
\hline $\begin{array}{l}\left(\log _{10}\right. \\
\mathrm{UI} / \mathrm{ml})\end{array}$ & $\mathrm{p}$ & & 0,2 & 0,02 \\
\hline \multicolumn{5}{|c|}{ Nhóm bệnh nhân TAF } \\
\hline & & \begin{tabular}{|c|}
0 tuần \\
$(\mathrm{n}=90)$
\end{tabular} & $\begin{array}{l}12 \text { tuân } \\
(\mathrm{n}=20)\end{array}$ & $\begin{array}{l}24 \text { tuân } \\
(\mathrm{n}=29)\end{array}$ \\
\hline \multirow{2}{*}{$\begin{array}{l}\mathrm{qHBsAg} \\
\left(\log _{10}\right. \\
\mathrm{UI} / \mathrm{ml}) \\
\end{array}$} & \multirow{2}{*}{$\begin{array}{c}\text { Giá trị } \\
\mathrm{p}\end{array}$} & $2,7 \pm 0,9$ & $2,6 \pm 1,0$ & $2,5 \pm 0,9$ \\
\hline & & & 0,8 & 0,4 \\
\hline
\end{tabular}

\section{BÀN LUÂN}

Nhiều nghiên cứu cho thấy qHBsAg là yếu tố dự đoán quan trọng chuyển huyết thanh $\mathrm{HBeAg}$ ở BN HBV mạn HBeAg dương điêu trị NAs. Trong nghiên cứu của Yang J. (2014) [4], thực hiện nghiên cứu trên $20 \mathrm{BN} \mathrm{HBeAg}$ dương điều trị TDF 96 tuần. Chuyển huyết thanh xảy ra vào tuân 24 đến 72 nếu $\mathrm{qHBsAg}$ giảm vào tuần 12 . Trong nghiên cứu chúng tôi có 250 BN với 160 $\mathrm{BN}(64 \%)$ được điều trị với TDF và $90 \mathrm{BN}(36 \%)$ được điều trị TAF. Thời gian điều trị trung bình của nhóm TDF là 4,1 năm và ở nhóm TAF là 2,5 năm. Giá trị qHBsAg trung bình tại thời điểm bắt đầu nghiên cứu của nhóm BN điều trị TDF là 3,0 $\pm 0,8\left(\log _{10} \mathrm{UI} / \mathrm{ml}\right)$ cao hơn có ý nghĩa so với nhóm $\mathrm{BN}$ đang điêu trị TAF $(2,7 \pm 0,9$ với $\mathrm{p}=0,02)$.

Trong nghiên cứu của Boglione L. (2013) [5], dân số nghiên cứu là 134 BN HBV mạn, điêu trị với Telbivudine, Lamivudine, Adefovir, ETV và TDF. Vào thời điểm 48 tuần, mức giảm qHBsAg thấp nhất ở Telbivudine, mạnh dần kế đến là Lamivudine, Adefovir, ETV và mạnh nhất là ở TDF $\left(0,45 \log _{10} \mathrm{UI} / \mathrm{ml}\right.$ so với $0,12 \log _{10} \mathrm{UI} / \mathrm{ml}, \mathrm{p}<$ $0,001)$. Thời gian ước tính mất $\mathrm{HBsAg}$ đối với TDF là 17 năm so với 63 năm ở BN điều trị
Telbivudine. Nhiều nghiên cứu được thực hiện ở nhiều nơi với các loại genotypes khác nhau, cho thấy $\mathrm{qHBsAg}$ ban đầu trước điều trị NAs hoặc qHBsAg giảm trong giai đoạn đâu (khoảng 24 tuần) thường là yếu tố dự đoán tốt của đáp ứng điều trị. Ngưỡng cắt của $\mathrm{qHBsAg}<2-3 \log _{10}$ $\mathrm{UI} / \mathrm{ml}$ được sử dụng để ngưng điều trị [6].Trong nghiên cứu của chúng tôi, nhóm BN được điều trị TDF sau 12 tuần theo dõi ghi nhận được 31 BN có kết quả xét nghiệm qHBsAg, giá trị qHBsAg trung bình giảm không đáng kể so với thời điểm bắt đâu theo dõi $(2,8 \pm 1,0$ so với 3,0 $\pm 0,8$ và $p=0,2)$. Tuy nhiên, tại thời điểm 24 tuần, ghi nhận được $58 \mathrm{BN}$ với giá trị $\mathrm{qHBsAg}$ trung bình là $2,7 \pm 0,9\left(\log _{10} \mathrm{UI} / \mathrm{ml}\right)$, giảm đáng kể $\left(0,3 \log _{10} \mathrm{UI} / \mathrm{ml}\right)$ so với thời điểm bắt đầu theo dõi, với $p=0,02$.

Trong nhóm BN điều trị TAF, ghi nhận được $20 \mathrm{BN}$ tại thời điểm 12 tuần với giá trị qHBsẢg trung bình là $2,6 \pm 1,0\left(\log _{10} \mathrm{UI} / \mathrm{ml}\right)$, giảm không có ý nghĩa (so với $2,7 \pm 0,9 ; p=0,8$ ). Tương tự, tại thời điểm 24 tuần, giá trị qHBsAg trung bình của $29 \mathrm{BN}$ là $2,5 \pm 0,9\left(\log _{10} \mathrm{UI} / \mathrm{ml}\right)$ giảm 0,2 $\log _{10} \mathrm{UI} / \mathrm{ml}$ so với thời điểm bắt đầu theo dõi, tuy nghiên sự thay đổi không có ý nghĩa thống kê. Sự thay đổi giữa hai nhóm có sự khác biệt có thể giải thích do giá trị qHBsAg ban đầu của hai nhóm có sự khác nhau, giá trị qHBsAg ở nhóm TDF cao hơn nhóm TAF có ý nghĩa thống kê ( $p=$ 0.02). Có rất nhiều nghiên cứu đã chứng minh mối tương quan giữa qHBsAg với HBV DNA với mức độ từ trung bình đến mạnh ở nhóm BN HBV mạn $\mathrm{HBeAg}$ dương và không có mối tương quan ở nhóm BN HBeAg âm $[6,7,8]$. Do đó, qHBsAg có thể được sử dụng thay thể cho xét nghiêm HBV DNA ở nhóm BN HBeAg dương tại những nơi còn hạn chế về kỹ thuật và kinh tế. Nghiên cứu chúng tôi ghi nhận được mức giảm qHBsAg trong quá trình điều trị TDF hoặc TAF có sự khác nhau tại các thời điểm 12 tuần và 24 tuần. Tuy nhiên, nghiên cứu có hạn chế do không ghi nhận được giá trị qHBsAg tại thời điểm bắt đầu điều trị thuốc và không theo dõi đủ lâu nên chưa ghi nhận được trường hợp nào mất HBsAg. Tóm lại, qHBsAg là xét nghiệm quan trọng, không những giúp xác định nhiếm HBV đang tiến triển mà còn góp phần xác định diễn tiến lâm sàng và đánh giá kết quả điều trị. HBV DNA được dùng để chẩn đoán giai đoạn, quyết định điêu trị, theo dõi đáp ứng điều trị. Tuy nhiển, bản chất HBV DNA dao động theo thời gian, kỹ thuật phức tạp, cần thời gian chờ đợi kết quả, đắt tiền và nhất là không thích hợp cho những trường hợp cần kết quả nhanh để xử trí đặc hiệu. Trong khi đó, 
qHBsAg kỹ thuật đơn giản, kết quả nhanh, chi phí thấp, tự động hóa $[6,8]$.

\section{KẾT LUẬN}

Nghiên cứu cho thấy giá trị qHBsAg giảm có ý nghĩa tại thời điểm 24 tuần trong quá trình điều trị TDF, tuy nhiên giá trị qHBsAg giảm không có ý nghĩa trong quá trình điều trị TAF thời gian ngắn. Trong tương lai cần có nhiều nghiên cứu với cõ̃ mẫu lớn hơn, đa trung tâm và thời gian theo dõi dài hơn đến đánh giá vai trò của qHBsAg trong quá trình điều trị.

\section{TÀI LIÊU THAM KHẢO}

1. World Health Organization. Guidelines for the Prevention, Care and Treatment of Persons with Chronic Hepatitis B Infection. 2015. https://apps. whoint/iris.

2. Hipgrave D B, Nguyen $T$ V, Vu M H, Hoang $T$ $\mathbf{L}$, et al. Hepatitis $B$ infection in rural Vietnam and the implications for a national program of infant immunization. American Journal of Tropical Medicine and Hygiene. 2003; 69(3): 288-294.

3. Gao $Y$, Li $Y$, Meng $Q$, Zhang $Z$, et al. Serum Hepatitis B Virus DNA, RNA, and HBsAg: Which Correlated Better with Intrahepatic Covalently
Closed Circular DNA before and after Nucleos(t)ide Analogue Treatment?. Journal of Clinical Microbiology. 2017; 55(10): 2972-2982.

4. Yang J, Chen J, Ye $P$, Jin $L$, et al. HBsAg as an important predictor of $\mathrm{HBeAg}$ seroconversion following antiviral treatment for $\mathrm{HBeAg}$-positive chronic hepatitis B patients. Journal of Translational Medicine. 2014; 12: 183.

5. Boglione L, D'Avolio A, Cariti G, Gregori G, et al. Kinetics and prediction of HBsAg loss during therapy with analogues in patients affected by chronic hepatitis $\mathrm{B}$ HBeAg negative and genotype D. Liver International. 2013; 33(4): 580-585.

6. Yang N, Feng J, Zhou T, Li Z, et al. Relationship between serum quantitative HBsAg and HBV DNA levels in chronic hepatitis B patients. Journal of Medical Virology. 2018; 90(7): 1240-1245.

7. Lee J H, Kím S J, Ahn S $H$, Lee J, et al. Correlation between quantitative serum HBsAg and HBV DNA test in Korean patients who showed high level of HbsAg. Journal of Clinical Pathology. 2010; 63 (11): 1027-1031

8. Liu $X$, Chen J M, Lou J L, Huang $Y X_{\text {, et al. }}$ Correlation between hepatitis B virus DNA levels and diagnostic tests for HBsAg, HBeAg, and PreS1$\mathrm{Ag}$ in chronic hepatitis B. Genetics and Molecular Research. 2016; 15(2): 1-9.

\section{KHẢO SÁT ĐĂC ĐIỂM THIẾU MÁU Ở BỆNH NHÂN BỆNH THẬN MẬN GIAI ĐOẠN CUỐI LỌC MÁU CHU KỲ}

\section{TÓM TẮT}

Mục tiêu nghiên cứu: Khảo sát đặc điểm thiếu máu và một số yếu tố liên quan đến thiếu máu ở bệnh nhân bệnh thận mạn giai đoạn cuối lọc máu chu kỳ. Phương pháp nghiên cứu: Nghiên cứu mô tả cằt ngang được thực hiên để khảo sát đặc điểm thiếu máu và các yếu tố liền quan ở 130 bệnh nhân bệnh thân mạn giai đoạn cuối lọc máu chu kỳ tai khoa Nội thẩn - thận nhân tạo Bệnh viện hữu ngḥi đa khoa Nghệ An. Kết quả: Tỷ lệ bệnh nhân bệnh thận mạn giai đoạn cuối lọc máu chu kỳ có thiếu máu là $92,3 \%$. Thiếu máu nhẹ chiếm tỷ lệ cao nhất $(48,5 \%)$, thiếu máu vứa chiếm tỷ lệ $37,7 \%$ và thiếu máu mức độ nặng chiếm tỷ lệ $6,2 \%$. Thiếu máu đẳng sắc là loại thiếu máu thường gặp nhất ở bệnh nhân bệnh thận mạn giai đoạn cuối lọc máu chu kỳ $(83,3 \%)$. Có mối liên quan giứa mức độ thiếu máu với tình trạng dinh dưỡng của bệnh nhân. Kết luận: Thiếu máu còn chiếm tỷ lệ cao ở bệnh nhân bệnh thận mạn giai

\section{*Đai hoc Y khoa Vinh}

Chịu trách nhiệm chính: Nguyễn Văn Tuấn

Email: tuanminh1975@gmail.com

Ngày nhận bài: 13.4.2021

Ngày phản biện khoa học: 26.5.2021

Ngày duyệt bài: 10.6.2021

\section{Nguyễn Văn Tuấn*, Trần Thị Anh Tho*}

đoạn cuối lọc máu chu kỳ. Có mối liên quan giữa mức độ thiếu máu với tình trạng dinh dưỡng của bệnh nhân.

Tứ khóa: thiếu máu, bệnh thận mạn giai đoạn cuối

\section{SUMMARY \\ SURVEYING ANEMIA'S CHARACTERISTICS OF PATIENTS WITH END STAGE RENAL DISEASE ON DIALYSIS}

Objective: To investigate the characteristics of anemia and some factors related to anemia in patients with end-stage renal disease (ESRD) on dialysis. Method: A cross-sectional descriptive study was conducted to investigate the characteristics of anemia and factors related to anemia in 130 patients with ESRD on dialysis at the Department of Internal Medicine - Hemodialysis at the Nghe An Friendship General Hospital. Results: Prevalence of patients with ESRD on dialysis that had anemia is $92,3 \%$. Propotion of patients with mild anemia was highest $(48,5 \%)$, propotion of patients with moderate anemia was $37,7 \%$ and proportion of patients with severity anemia was $6,2 \%$. Ormochromic anemia was the most common type of anemia in patients with ESRD on dialysis $(83,3 \%)$. There was a relationship between the degree of anemia and the nutritional status of the patient. Conclusions: The proportion of anemia was high in patients with ESRD on dialysis. There was a 